\title{
Prevalence of depression and its association with parental neglect among adolescents at governmental high schools of Aksum town, Tigray, Ethiopia, 2019: A cross sectional study
}

\section{Enguday Tirfeneh}

Aksum University

Mengesha Srahbzu ( $\square$ mengusew@gmail.com )

Aksum university https://orcid.org/0000-0002-6486-3732

Research article

Keywords: Depression, high school, parental neglect

Posted Date: December 1st, 2019

DOl: https://doi.org/10.21203/rs.2.17823/v1

License: (c) (i) This work is licensed under a Creative Commons Attribution 4.0 International License.

Read Full License 


\section{Abstract}

Background depression is one of the most serious and prevalent mental illnesses that can result in serious disability and ending life by committing suicide and homicide. The risks of having depression are substantially higher in persons who have parental neglect when compared to the general population.

Objective To detect prevalence of depression and its association with parental neglect among adolescents in governmental high schools at Aksum town, Tigray, Ethiopia 2019

Method A facility based cross-sectional study was conducted from January 1-30/2019 at Aksum town high schools. Public health questionnaire was used in this study to detect Depression. Study participants were selected using simple random sampling technique. Data was collected with face to face interview. Data was analyzed using statistical package for social science version 22. Bivariate and multivariate logistic regressions were used to see the association between depression and parental neglect. Adjusted Odds ratio at a p-value $<0.05$ with $95 \%$ confidence interval was taken to declare statistical significance of variables.

\section{Background}

Adolescence (10-19 years) is among age group which highly experiences several factors in their day to day activities (1). Adolescent age group is also a time that individuals will experience physical changes and take different responsibilities which may give rise to get mental disorders as it is a new environment for them. Youths constitute almost one-third of the world's population and among that one-third of them live in the developing world, where they form up to half of the population (2).

Child or adolescent abuse is an issue concerning millions of youths and their families worldwide. Maltreatment of youths can be defined as an act of omission or commission by others who are caregivers that may have danger, possible for danger or threats of danger to adolescents (3). Parental neglect involves an act of omission, and it is defined as a failure by a caregiver to address the adolescents' basic physical, emotional, medical/dental or educational needs $(4,5)$.

The burden of psychiatric disorders on youths is enormous and covers a great number of people in all types of societies. The majority of psychiatric disorders begin at an early age (12-24), even though they are supposed to be experienced in older individuals later in life. Depression is the most common and severe psychiatric disorder that leads to magnifying problems in an adolescent's capacity to take care of his or her everyday responsibilities and functionalities. Depressive disorders in adolescents result in a horrible consequences even to other healthy components. It may lead to educational impairment, comorbid psychoactive substance abuse, behavioral difficulties and risky reproductive and sexual practices (6).

A mental health service for adolescents' mental health problems is not adequate yet, even in the developed world. Age-related stigma is among the major contributory factors for unmet mental health 
needs in youths (7). Currently, depression is recognized as the first psychiatric disorder of youths which is related to its common presentation, episodic nature and its ability to cause significant complications and impairment. According to the 2009 discussion paper released by world health organization (WHO), among 66 million individuals experiencing depression; 85\% live in the developing world (8).

Some statistics indicate that depression is as frequent as $20 \%$ common in adolescents (9) and $43.4 \%$ of high school students in Tehran to be depressed (10). A study which was conducted between China and America using the Chinese version of the beck depression inventory reported that $15 \%$ of participants had depression among 503 subjects (11). Another study in New York revealed the magnitude of depression in high school students to be $34 \%$ (12). Another survey, using a summarized self-administered Beck's questionnaire, reported severe depression in $18 \%$ of 8,206 adolescents (13).

A school-based cross-sectional survey was conducted in South India to estimate the prevalence of depression among school-going adolescents. In this, a total of 2432 school-going adolescents were included in the study and $25 \%$ of them have been found to have depression (14).

Though depression is one of the major diseases that cause failure to socialize among youths, it is often neglected and has not been given adequate attention it needs. The scarcity services to emotional and other mental problems of children and adolescents make this study necessary for strong emphasis to be given for the support of mental health in Ethiopia for the sake of mental and behavioral welfare of growing children and adolescents (15).

\section{Methods}

\section{Study design, period and setting}

We conducted a facility-based cross-sectional study from January 1-30/2019. The study targeted adolescents at Aksum Town high schools. Aksum is located in the Tigray region which is $1024 \mathrm{Km}$ far from Addis Ababa. There are three high schools in Aksum town currently named Aksum secondary school, Atse Kaleb secondary school and Kedamay Minilik secondary school and there are a total of 2579 grade nine and 2241 grade ten students in the three high schools.

\section{Sample size calculation and sampling procedure}

We calculated the sample size using a single population proportion formula and we took the following assumptions; $95 \%$ confidence interval and $4 \%$ marginal error. The proportion of depression is: $(39.3 \%)$ from the previous study (16) and a non-response rate of $10 \%$. The final sample size was taken to be 630 . All governmental high schools found at Aksum town were included in our study. Students were accessed from each high school proportionally to their total number of students. Finally, respondents were selected for the study by simple random sampling i.e. lottery method.

\section{Data collection instrument and techniques}


Data was collected by face to face interview. Initially, screening tools and other developed structured questionnaire in English language was translated to Amharic and Tigrigna and back to English by independent person to check for consistency and understandability of the tool. Data was collected by six bachelor degree holder health professionals. The data collection process was supervised by the principal investigators. Training was given for data collectors for two days by the principal investigator regarding the process and techniques of data collection.

PHQ-9 was used to assess depression which is a multi-purpose instrument for screening, diagnosing, monitoring and measuring the severity of depression. PHQ 9 score of greater than or equal to 10 has sensitivity and a specificity of $88 \%$ for major depression. Adverse Childhood Experience Questionnaire (ACEQ) which is a 10 items screening tool was used to access parental neglect. ACEQ includes questions that assess emotional abuse and neglect, physical abuse and neglect, educational and medical neglect and sexual abuse (17).

The Oslo 3 social support scale was applied to know the level of social support towards adolescents. The scale divides the level of social support into three as poor social support (3-8), moderate social support (3-14) and strong social support (12-14) (reliability Cronbach's $a=0.91)(18)$.

\section{OPERATIONAL DEFINITIONS}

Adolescents: - For this study, a school-attending person specifically within the 15-19 years of age.

Depression: -Those who score great than 5 from the PHQ-9 scale (19).

Parental Neglect: - ACEQ which is a self-report instrument covering 10 items, to rate the severity of emotional abuse and neglect, physical abuse and neglect and sexual abuse (17).

Social support: - according to the Oslo-3 social support scale, a score of 3-8 is taken as poor support, 9-11 as moderate support and 12 and 14 as strong support (18).

\section{Data analysis and interpretation}

After the questionnaire was checked for cleanliness; data was entered using Epi-data 3.1 and exported to SPSS 22 statistical software for analysis. Socio-demographic characteristics of respondents were analyzed by descriptive statistics and presented in percentage, mean and standard deviations. Bivariate analysis was used to see the association between outcome and independent variable. Multivariate logistic regression was done for those variables whose $p$-value is less than 0.2 . The significance of variables was considered at $p$-value $<0.05$ and $95 \% \mathrm{Cl}$ of their respected adjusted odd ratio.

\section{Result}


A total of 624 participants with a response rate of $99.05 \%$ were included in the study. Among this 339 $(54.3 \%)$ were females. The age of the majority of students $246(39.4 \%)$ were known to be 15 years followed by 16 years of age 217(34.8\%) and more than half 328 (52.6\%) were grade 9 students. More than three fourth of participants 494 (79.2\%) were orthodox Christian religion followers. (Table 1)

Table 1- Distribution of Socio-demographic factors in high school students at Aksum town $(n=624)$ 


\begin{tabular}{|c|c|c|c|}
\hline \multicolumn{2}{|l|}{ Variable } & \multirow{2}{*}{$\begin{array}{l}\text { frequency } \\
285\end{array}$} & \multirow{2}{*}{$\begin{array}{l}\text { Percent (\%) } \\
45.7\end{array}$} \\
\hline Sex & Male & & \\
\hline & Female & 339 & 54.3 \\
\hline \multirow{5}{*}{ Age } & 15 & 246 & 39.4 \\
\hline & 16 & 217 & 34.8 \\
\hline & 17 & 78 & 12.5 \\
\hline & 18 & 63 & 10.1 \\
\hline & 19 & 20 & 3.2 \\
\hline \multirow[t]{2}{*}{ Grade } & grade9 & 328 & 52.6 \\
\hline & grade10 & 296 & 47.4 \\
\hline \multirow[t]{4}{*}{ Religion } & Orthodox & 494 & 79.2 \\
\hline & Muslim & 101 & 16.2 \\
\hline & Protestant & 24 & 3.8 \\
\hline & Other & 5 & .8 \\
\hline \multirow[t]{2}{*}{ Family size } & $1-5$ & 372 & 59.6 \\
\hline & $>5$ & 252 & 40.4 \\
\hline \multirow[t]{2}{*}{ Residence } & Urban & 422 & 67.6 \\
\hline & Rural & 202 & 32.4 \\
\hline \multirow[t]{5}{*}{ Father's occupation } & Farmer & 220 & 35.3 \\
\hline & Labor work & 32 & 5.1 \\
\hline & Merchant & 112 & 17.9 \\
\hline & Government Employee & 158 & 25.3 \\
\hline & Private Employee & 102 & 16.3 \\
\hline \multirow[t]{6}{*}{ Mother's occupation } & Farmer & 175 & 28.0 \\
\hline & Labor work & 38 & 6.1 \\
\hline & Merchant & 76 & 12.2 \\
\hline & Government employee & 107 & 17.1 \\
\hline & Private employee & 93 & 14.9 \\
\hline & housewife & 135 & 21.6 \\
\hline
\end{tabular}




\begin{tabular}{llll} 
Father's educational status & Illiterate & 83 & 13.3 \\
\cline { 2 - 4 } & 1-4thgrade & 162 & 26.0 \\
\cline { 2 - 4 } & 5-8thgrade & 143 & 22.9 \\
\cline { 2 - 4 } & 9-12thgrade & 112 & 17.9 \\
\cline { 2 - 4 } Mother's educational status & Certificate \& Above & 124 & 19.9 \\
\cline { 2 - 4 } & Illiterate & 176 & 28.2 \\
\cline { 2 - 4 } & 1-4thgrade & 136 & 21.8 \\
\cline { 2 - 4 } 5-8thgrade & 124 & 19.9 \\
\cline { 2 - 4 } & 9-12thgrade & 117 & 18.8 \\
\hline & Certificate \& Above & 71 & 11.4
\end{tabular}

\section{Social support related variables}

Among participants, the level of social support was measured. Based on the result of this study majority of $256(41 \%)$ students have been found to have poor social support followed by moderate social support $217(34.8 \%)$ and only $151(24.2 \%)$ of students were under good social support. (Figure 1 )

Figure 1: - Distribution of the level of social support among high school students at Aksum town, 2019 $(n=624)$

\section{Substance-related variables}

Regarding substance use among high school students at Aksum town, only 22(3.5\%) have chewed khat within their lifetime whereas only 14 (2.2\%) of students chewed khat within the last 3 months. 247 $(39.6 \%)$ of participants reported alcohol drinking in their lifetime while only $138(22.1 \%)$ of students drunk alcohol within the last 3 months. Regarding cigarette smoking, 26 (4.2\%) of the total participants smoke within their lifetime and 20(3.2\%) smoke cigarettes within the last 3 months. (Figure 2)

Figure 2: -Distribution of substance-related factors among high school students at Aksum town, 2019 $(n=624)$

\section{Parental neglect related variables}

Parental neglect among adolescents was assessed using the adverse childhood experience questionnaire in which the neglected part assessed physical and emotional neglect. Among the 624 adolescents who participated in this study, 334 (53.5\%) of the participants answered yes to one or more questions among the total 10 items of the adverse childhood experience questionnaire and females account 190 (56.9\%) of 
the total response. Among this figure of students experiencing parental neglect more than half 175 $(52.4 \%)$ of them were grade 9 students. (Table 2 )

Table 2:- Distribution of Adverse Childhood Experience questionnaire by sex and educational level among adolescents in the sampled governmental high schools in Aksum town, Ethiopia, $2019(n=624)$ 


\section{Variables}

Male Female Grade Grade Total

$\begin{array}{llll}(n, \%) & (n, \%) & 9(n, \%) & 10(n, \%)\end{array}$

Physically Hurt

$\begin{array}{lll}\text { Yes } & 74 & 116 \\ & (11.9) & (18.6)\end{array}$

$98(51.6)$

$92(48.4)$

190

$(30.5)$

No $211 \quad 223$

$230(53) \quad 204(47)$

434

(33.8) (35.7)

$(69.5)$

Hit you Marks of Injury

$\begin{array}{lllll}\text { Yes } & \begin{array}{l}34 \\ (5.5)\end{array} & 58(9.3) & 48(52.2) & 44(47.8) \\ & & & \\ \text { No } & \begin{array}{l}251 \\ (40.2)\end{array} & 281(45) & \begin{array}{l}280 \\ (52.6)\end{array} & \begin{array}{l}252 \\ (47.4)\end{array}\end{array}$

92

532

Sexual Abuse

$\begin{array}{ll}\text { Yes } & 26 \\ & (4.2)\end{array}$

$45(7.2)$

41 (57.7) $\quad 30(42.3)$

71

No $259 \quad 294$

(41.5)

(47.1)

287

(51.9)

286

(48.1)

No Love

Yes 41

\begin{tabular}{|c|c|c|c|c|c|c|}
\hline \multirow[t]{2}{*}{ No Love } & Yes & $\begin{array}{l}41 \\
(6.6)\end{array}$ & $67(10.7)$ & $51(47.2)$ & $57(52.8)$ & $\begin{array}{l}108 \\
(17.3)\end{array}$ \\
\hline & No & $\begin{array}{l}244 \\
(39.1)\end{array}$ & $\begin{array}{l}272 \\
(43.6)\end{array}$ & $\begin{array}{l}277 \\
(53.7)\end{array}$ & $\begin{array}{l}237 \\
(46.3)\end{array}$ & $\begin{array}{l}516 \\
(82.7)\end{array}$ \\
\hline \multirow[t]{2}{*}{ Not Enough Food or Protection } & Yes & $\begin{array}{l}35 \\
(5.6)\end{array}$ & $44(7)$ & $43(54.4)$ & $36(45.6)$ & $\begin{array}{l}79 \\
(12.6)\end{array}$ \\
\hline & No & $\begin{array}{l}250 \\
(40.1)\end{array}$ & $\begin{array}{l}295 \\
(47.3)\end{array}$ & $\begin{array}{l}285 \\
(52.3)\end{array}$ & $\begin{array}{l}260 \\
(47.7)\end{array}$ & $\begin{array}{l}545 \\
(87.4)\end{array}$ \\
\hline \multirow[t]{2}{*}{ Divorced Parents } & Yes & $31(5)$ & $49(7.9)$ & $41(51.3)$ & $39(48.7)$ & $\begin{array}{l}80 \\
(12.8)\end{array}$ \\
\hline & No & $\begin{array}{l}254 \\
(40.7)\end{array}$ & $\begin{array}{l}290 \\
(46.5)\end{array}$ & $287(52.8)$ & 257(47.2) & $\begin{array}{l}544 \\
(87.2)\end{array}$ \\
\hline \multirow[t]{2}{*}{ Abuse with Gun or Knife } & Yes & $\begin{array}{l}20 \\
(3.2)\end{array}$ & $29(4.6)$ & $28(57.1)$ & $21(42.9)$ & $\begin{array}{l}49 \\
(7.8)\end{array}$ \\
\hline & No & $\begin{array}{l}265 \\
(42.6)\end{array}$ & $\begin{array}{l}310 \\
(49.6)\end{array}$ & $\begin{array}{l}300 \\
(52.2)\end{array}$ & $\begin{array}{l}275 \\
(47.8)\end{array}$ & $\begin{array}{l}575 \\
(92.2)\end{array}$ \\
\hline \multirow[t]{2}{*}{ Live With Alcoholic or Drug User } & Yes & $\begin{array}{l}29 \\
(4.6)\end{array}$ & $42(6.7)$ & $40(56.3)$ & $31(43.7)$ & $\begin{array}{l}71 \\
(11.3)\end{array}$ \\
\hline & No & $\begin{array}{l}256 \\
(41)\end{array}$ & $\begin{array}{l}297 \\
(47.6)\end{array}$ & $\begin{array}{l}288 \\
(52.1)\end{array}$ & $\begin{array}{l}265 \\
(47.9)\end{array}$ & $\begin{array}{l}553 \\
(88.7)\end{array}$ \\
\hline \multirow[t]{2}{*}{$\begin{array}{l}\text { Depressed or Attempted Suicide } \\
\text { HH Member }\end{array}$} & Yes & $19(3)$ & $28(4.5)$ & $31(66)$ & $16(34)$ & $\begin{array}{l}47 \\
(7.5)\end{array}$ \\
\hline & No & $\begin{array}{l}266 \\
(42.5)\end{array}$ & $\begin{array}{l}311 \\
(49.8)\end{array}$ & $\begin{array}{l}297 \\
(51.5)\end{array}$ & $\begin{array}{l}280 \\
(48.5)\end{array}$ & $\begin{array}{l}577 \\
(92.5)\end{array}$ \\
\hline Household Member in Prison & Yes & 41 & $46(7.4)$ & $50(57.5)$ & $37(42.5)$ & $87(14)$ \\
\hline
\end{tabular}

$57(52.8)$

553 


\begin{tabular}{lllllll}
\hline & No & 244 & $293(47)$ & 278 & 259 & 537 \\
& $(39.1)$ & & $(51.8)$ & $(48.2)$ & $(86)$ \\
\hline Parental neglect & Yes & 144 & 190 & $175(52.4)$ & $159(47.6)$ & 334 \\
& & $(23.1)$ & $(30.4)$ & & & $(53.5)$ \\
\cline { 2 - 7 } & No & 141 & 149 & $153(52.8)$ & $137(47.2)$ & 290 \\
& & $(22.6)$ & $(23.9)$ & & & $(46.5)$
\end{tabular}

\section{Prevalence of depression}

The study showed that the prevalence of depression was $226(36.2 \%)$ with $95 \% \mathrm{Cl}(32.3,40.2)$. The prevalence rate was higher among grade 10 students since 110/296 (37.2\%) of grade 10 students met the screening criteria for depression which is higher when compared to $116 / 328(35.4 \%)$ of grade 9 students met the screening criteria for depression in the study. According to the PHQ-9 severity classification from the total students under depression, $133(21.3 \%)$ of students lie in mild depression category whereas $74(11.4 \%), 15(2.4 \%)$ and $7(1.1 \%)$ of students were found to have moderate, moderately severe and severe depression respectively. (Figure 3)

Figure 3:- characterization of depression severity among adolescents in governmental high schools at Aksum town, 2019 ( $n=624)$

\section{Association between depression and parental neglect}

Adverse childhood questionnaire which assesses physical neglect, educational neglect, emotional neglect, and medical neglect was used to assess the main independent variable. Physical neglect refers to parents' negligence to provide adequately nutritious meals consistently, or it might mean that a parent has abandoned their child. Educational neglect is a failure to provide a child with adequate education in the form of enrolling them in school or providing adequate homeschooling. Emotional neglect is consistently ignoring, rejecting, verbally abusing, teasing, withholding love, isolating or terrorizing a child. Medical neglect is, in turn, the failure to provide appropriate health care for a child (although financially able to do so) (20).

The adverse childhood experience questionnaire was checked for co-linearity between each item using the Pearson correlation coefficient at the $p$-value of $<0.05$. As a result, there was no co-linearity found between each item of the screening tool. A reliability test was conducted among the 10 items and it has been found to have high reliability (Cronbach's alpha $=0.83$ ). After it is checked for co-linearity it was entered into logistic regression analysis and it is found to have a p-value of $<0.25$ on bivariate analysis crude odd ratio ( $\mathrm{COR}=2.75,95 \% \mathrm{Cl}(1.95,3.89)$, $\mathrm{p}$-value $=0.000)$. 
In addition to parental neglect, bivariate analysis was done for other explanatory variables for depression and the result revealed that explanatory variables; sex, family size, father education, mother education, social support and current use of alcohol were found to have $p$-value $<0.2$ (Table 3 ).

These factors were entered into multivariate logistic regression for further analysis to control confounding effects. As a result being female, poor social support, mother educational status and parental neglect are found to be statistically significant for depression at $p$-value $<0.05$.

The odds of developing depression among those who had parental neglect were 2.61 times higher as compared to those who haven't parental neglect (AOR=2.61, 95\% Cl: $(1.83,3.72))$. (Table 3)

Table 3:- bivariate and multivariate logistic analysis of factors associated with depression among adolescents in the sampled governmental high schools in Aksum town, Ethiopia, 2019 ( $n=624)$ 


\begin{tabular}{|c|c|c|c|c|c|c|}
\hline \multirow{2}{*}{ Variable } & \multirow[t]{2}{*}{ Category } & \multicolumn{2}{|c|}{ Depression } & \multirow{2}{*}{ COR $(95 \% \mathrm{Cl})$} & \multirow{2}{*}{ AOR $(95 \% \mathrm{Cl})$} & \multirow[t]{2}{*}{$\mathrm{p}$-value } \\
\hline & & yes & No & & & \\
\hline \multirow[t]{2}{*}{ Sex } & Male & 83 & 202 & 1 & 1 & \\
\hline & Female & 226 & 398 & $1.78(1.27,2.48)$ & $\begin{array}{l}1.48(1.03 \\
2.13)\end{array}$ & $.034^{\star}$ \\
\hline \multirow[t]{2}{*}{ Family size } & $<=5$ & 143 & 229 & 1 & 1 & \\
\hline & $>5$ & 83 & 169 & $0.79(0.56,1.10)$ & $\begin{array}{l}0.77 \\
(0.53,1.10)\end{array}$ & .150 \\
\hline \multirow[t]{3}{*}{ Social support } & Poor & 107 & 149 & $1.86(1.21,2.88)$ & $1.69(1.07,2.69)$ & $.026 *$ \\
\hline & Moderate & 77 & 140 & $1.43(0.91,2.24)$ & $1.56(0.97,2.52)$ & .067 \\
\hline & Good & 42 & 109 & 1 & 1 & \\
\hline \multirow[t]{2}{*}{ Current alcohol } & Yes & 98 & 149 & $1.28(0.918,1.784)$ & $0.73(.51,1.06)$ & .100 \\
\hline & No & 128 & 249 & 1 & 1 & \\
\hline \multirow[t]{5}{*}{$\begin{array}{l}\text { Mother } \\
\text { education }\end{array}$} & Illiterate & 75 & 99 & $2.07(1.13,3.80)$ & $\begin{array}{l}2.21 \\
(1.09,4.49)\end{array}$ & $.028^{*}$ \\
\hline & $1-4$ & 49 & 86 & $1.56(0.83,2.93)$ & $\begin{array}{l}1.45(0.70 \\
3.01)\end{array}$ & .317 \\
\hline & $5-8$ & 47 & 79 & $1.63(0.861,3.08)$ & $1.67(0.83,3.35)$ & .153 \\
\hline & $9-12$ & 36 & 82 & $1.20(0.62,2.31)$ & $1.27(.64,2.56)$ & .496 \\
\hline & $\begin{array}{l}\text { College and } \\
\text { above }\end{array}$ & 19 & 52 & 1 & 1 & \\
\hline \multirow{5}{*}{$\begin{array}{l}\text { Father } \\
\text { education }\end{array}$} & Illiterate & 35 & 46 & $1.81(1.01,3.24)$ & $1.11(.56,2.20)$ & .768 \\
\hline & $1-4$ & 62 & 101 & $1.46(0.89,2.40)$ & $\begin{array}{l}0.92(.495 \\
1.706)\end{array}$ & .789 \\
\hline & $5-8$ & 56 & 87 & $1.53(0.92,2.55)$ & $\begin{array}{l}1.11 \\
(0.61,2.03)\end{array}$ & .730 \\
\hline & $9-12$ & 36 & 76 & $1.13(0.65,1.96)$ & $1.00(.55,1.83)$ & .997 \\
\hline & $\begin{array}{l}\text { College and } \\
\text { above }\end{array}$ & 37 & 88 & 1 & 1 & \\
\hline \multirow[t]{2}{*}{ Parental neglect } & Yes & 156 & 178 & $2.75(1.95,3.89)$ & $\begin{array}{l}2.61 \\
(1.83,3.72)\end{array}$ & $.000 \star \star \star$ \\
\hline & No & 70 & 220 & 1 & 1 & \\
\hline
\end{tabular}




\section{Discussion on the prevalence of depression}

The study revealed that the prevalence of depression was $36.2 \%$. This result was in line with studies conducted at Addis Ababa (39.3\%) among adolescents in governmental high schools (16) and Northern Iran 34\% among high school and pre-university adolescents using Beck's questionnaire (21).

However, the current study finding for depression was higher than the studies conducted among adolescents at Korea 20.6\% (22), Saudi Arabia 23.8 (23), Egypt 28.6\% (24), Malaysia 10.3\% (25) and Trinidad $25.3 \%(26)$.The reason for the above difference might be due to difference in adolescents age which was only 13-19 in Trinidad (26), study population who were only boys in Korea (22), type of study conducted which was a large survey in Ethiopia (27), screening tool which was BDI II in a study conducted at Saudi Arabia (23) and the children's depression inventory in a study at Malaysia (25) and sample size which was 1373 in Egypt (24).

On the other hand, the finding of this study on the prevalence of depression was lower than a study conducted at Can Tho-City, Vietnam 41.1\% (28) and China Hong Kong 50\% (29). This difference might be attributed to time point the studies conducted which was a long-term study in Hong Kong (29), difference in study subjects in which only those adolescents who are abused physically and emotionally were studied and difference in sample size in which large sample size was used in Vietnam i.e.1159 students (28).

The above difference might also be due to differences in screening tools used to determine depression in which the Center for Epidemiology Studies Depression Scale (CES-D) was used in a study conducted at Can Tho-City, Vietnam (28).

Regarding the severity of depression, the prevalence of mild depression was in line with a study conducted in Egypt which was 21.5\%. However, the result of this study for moderate and severe depression is higher than a study conducted in Egypt which was 7.1\% and 0\% in Egypt respectively (24) and Iran $5.7 \%$ and $0.3 \%$ respectively (21).

The result of this study on mild depression is also found to be lower than a study conducted in Iran among high school and pre-university adolescents which was $28 \%$ (21). A possible reason for the difference might be difference screening tools used to determine depression such as CES-D was applied in Iran (21) and sample size which was 1373 in Egypt (24).

\section{Discussion on the association between depression and parental neglect}

Parental neglect which is the main independent variable is found to be statistically associated with depression at $p$-value $<0.05$. It was tried to analyze the students' parental neglect with other explanatory variables to control for confounding variables. After multivariate analysis, the strength of association between depression and parental neglect doesn't show a significant difference i.e. COR=2.75 and $\mathrm{AOR}=2.61$. 
Students who were experiencing parental neglect were 2.61 times more likely to develop depression than those who didn't experience parental neglect. This study is in line with a study conducted at Addis Ababa $(A O R=2.9)(16)$. This may be because among the most common outcomes of neglect is the failure to succeed. Breakdown to succeed is a term that is normally applied to explain kids with a strange prototype of weight gain or weight loss, or experiencing inadequate growth patterns (both mental and physical health) per a kid's age and developmental phase. This situation can occur when a child does not get sufficient diet or necessary medical consideration essential for appropriate bodily development (30); which may later hinder adolescents' overall physical health including mental health and lead them to depression.

In more tremendous cases breakdown to succeed can also influence children over their entire existence course by really destructing his/her cognitive progress and his/her immune system due to inadequate calorie intake or lack of therapeutic consideration, making the child lose developmental milestones to a great extent and a great extent prone to poor health even afterward adulthood and give way to depression (30).

It might also be because a preponderance of neglected kids displays attachment disorder manifestations and finally form timid connections even to their close families. This disturbed attachment to their primary caregiver alters their upcoming interaction with peers by making them emotional and physically isolated from others and this intern reducing the possibility of forming true relations. Moreover, as a result of their precedent abuse, neglected children experience that forming close relationships with others loses their control in life and exposes them by raising their susceptibility (31).

Neglectful parents and caregivers give poor interaction and positivity for their belongings which is linked to increased levels of shame called shame-proneness (32). Shame-proneness may increase neglected adolescent's risk for depressive symptoms since they try to suppress such an aversive feeling. Shame suppression, in turn, may lead to sadness, social isolation and withdrawal and lastly to depression (33, 34).

The development of the brain may continue beyond adolescence age group. Therefore, neglectful experiences may impose a lasting effect on the continuing need for optimal conditions for development of some structures concerned with attention, emotional regulation, which contributes for the heightened occurrence of depression on victims (35).

The increased occurrence of depression in those who are experiencing parental neglect might also be due to the reason that neglected children show trouble in regulating their feeling, appreciate others' emotional expression and trouble in differentiating emotions which amplify their susceptibility for developing depression. Youth with a history of neglect during their early ages may also have stressful reminders which contributes to their current depressive state by suppressing and leads to deregulation of their emotion (36). 
The higher prevalence of depression may also be a result of the injured hippocampus, as there are elevated levels of stress hormones such as cortisol due to increased stress levels in youths who had experienced neglect. This increased release of stress hormone is assumed to have an injury on the hippocampus; cortical area implicated in diverse brain function and this, in turn, gives rise for developing depression in youths (37).

\section{Conclusions And Recommendations}

In the current study, the prevalence of depression is found to be high when compared to other populations. A significant and strong association is also determined between parental neglect and depression.

\section{To school teachers}

It is good if school teachers give emphasize to those students who seem psychologically unwell. It is better if school teachers exercise recommending such students to school psychologists.

\section{To researchers}

It is good to conduct a prospective cohort study to investigate the temporal relationship between factors and depression.

\section{To Aksum university comprehensive hospital}

It is good if Aksum university comprehensive hospital start campaign which will teach about the effect of parental neglect on the adolescent's mental health. Then, it is good to start clinic service for students who are psychologically unwell including consultation service.

\section{Abbreviations}

ACEQ: Adverse Childhood Experience Questionnaire, AOR: Adjusted Odd Ratio, CDI: childhood depression inventory, CES-D: Center for Epidemiology Studies Depression scale, Cl: Confidence Interval, COR: Crude Odd Ratio, PHQ-9: Patient Health Questionnaire, SPSS 22: Statistical Package for Social Science Version 22, WHO: World Health Organization

\section{Declarations}

\section{Ethics approval and consent to participate}

Ethical clearance was obtained from the ethical review board of the Institute of Health, Aksum University. Written consent was asked from each selected student after they are informed about the nature, purposes, benefits and adverse effects of the study and invited to participate. Written assent was also obtained from those who are under 18 years old from their parents/guardians/teachers. Confidentiality 
was ensured. Participants were strictly informed as they have the right to refuse or discontinue participation at any time.

\section{Consent for publication}

Not applicable

\section{Availability of data and materials}

All the data included in the manuscript can be accessed from the corresponding author Mengesha Srahbzu upon request through email address of mengusew@gmail.com.

\section{Funding}

No specific fund is secured for this study.

\section{Competing interests}

The authors declare that they have no competing interest

\section{Authors' Contributions}

ET and MS originated the idea and wrote the proposal, participated in data collection, analyzed the data and drafted the paper. All authors read and approved the final version of the manuscript.

\section{Acknowledgment}

First, we would like to thank Aksum University for granting the research financially and materially. We would like to extend our heartfelt thanks to Aksum University College of health science research office and ethical review committee for their timely cooperation.

We would like also to praise our thanks to the Aksum town education office and each governmental high school head office for their cooperation during the data collection period. We would like to extend our thanks to the study participants. Finally, we would like to thank Mr. Melsew Belachew and Mr. Mekuanint Mihret (English language experts) for helping us in language and grammar corrections while we revise our manuscript.

\section{References}

1. Patel V, Flisher AJ, Hetrick S, McGorry P. Mental health of young people: a global public-health challenge. the Lancet. 2007;369(9569):1302-13.

2. Black RE, Cousens S, Johnson HL, Lawn JE, Rudan I, Bassani DG, et al. Global, regional, and national causes of child mortality in 2008: a systematic analysis. The lancet. 2010;375(9730):1969-87. 
3. Marcdante K, Kliegman RM. Nelson Essentials of Pediatrics-E-Book: First South Asia Edition: Elsevier Health Sciences; 2016.

4. Widom CS, Czaja S, Dutton MA. Child abuse and neglect and intimate partner violence victimization and perpetration: A prospective investigation. Child abuse \& neglect. 2014;38(4):650-63.

5. Franks SB, Mata FC, Wofford E, Briggs AM, LeBlanc LA, Carr JE, et al. The effects of behavioral parent training on placement outcomes of biological families in a state child welfare system. Research on Social Work Practice. 2013;23(4):377-82.

6. Kumar KS, Srivastava S, Paswan S, Dutta AS. Depression-symptoms, causes, medications and therapies. The Pharma Innovation. 2012;1(3, Part A):37.

7. Reading R. Mental health of young people: a global public-health challenge. Child: Care, Health and Development. 2007;33(5):647-8.

8. Organization WH. ECOSOC meeting addressing noncommunicable diseases and mental health: major challenges to sustainable development in the 21st century. World Health Organization. 2009:132.

9. Milne LC, Lancaster S. Predictors of depression in female adolescents. Adolescence. 2001;36(142):207.

10. Yazdani M, Yazdannik A. Association between Behavioral Patterns of Parents with Depression and Suicidal Thoughts among Adolescents. journal of shahrekord university of medical sciences. $2001 ; 3(2)$.

11. Yeung A, Howarth S, Chan R, Sonawalla S, Nierenberg AA, Fava M. Use of the Chinese version of the Beck Depression Inventory for screening depression in primary care. The Journal of nervous and mental disease. 2002;190(2):94-9.

12. Sukhodolsky DG, Kassinove H, Gorman BS. Cognitive-behavioral therapy for anger in children and adolescents: A meta-analysis. Aggression and violent behavior. 2004;9(3):247-69.

13. Kandel DB, Davies M. Epidemiology of depressive mood in adolescents: An empirical study. Archives of general psychiatry. 1982;39(10):1205-12.

14. Malik M, Khanna P, Rohilla R, Mehta B, Goyal A. Prevalence of depression among school going adolescents in an urban area of Haryana, India. International Journal Of Community Medicine And Public Health. 2017;2(4):624-6.

15. Desta M. Epidemiology of child psychiatric disorders in Addis Ababa, Ethiopia: Barn-och ungdomspsykiatri; 2008.

16. seid S. Prevalence of Depression among Adolescents and Association of Parental Neglect on Depression in Governmental Preparatory Schools in Addis Ababa, Ethiopia 2017 [Available from: http://localhost/xmlui/handle/123456789/12343.

17. Murphy A, Steele M, Dube SR, Bate J, Bonuck K, Meissner P, et al. Adverse childhood experiences (ACEs) questionnaire and adult attachment interview (AAI): Implications for parent child relationships. Child Abuse \& Neglect. 2014;38(2):224-33. 
18. Abiola T, Udofia O, Zakari M. Psychometric properties of the 3-item oslo social support scale among clinical students of Bayero University Kano, Nigeria. Malaysian Journal of Psychiatry. 2013;22(2):3241.

19. Terasaki DJ, Gelaye B, Berhane Y, Williams MA. Anger expression, violent behavior, and symptoms of depression among male college students in Ethiopia. BMC public health. 2009;9(1):13.

20. Lopez P, Allen PJ. Addressing the health needs of adolescents transitioning out of foster care. Pediatric Nursing. 2007;33(4).

21. Modabber-Nia M-J, Shodjai-Tehrani H, Moosavi S-R, Jahanbakhsh-Asli N, Fallahi M. The prevalence of depression among high school and preuniversity adolescents: Rasht, northern Iran. Arch Iran Med. 2007;10(2):141-6.

22. Cho SJ, Jeon HJ, Kim MJ, Kim JK, Kim US, Lyoo IK, et al. Prevalence and correlates of depressive symptoms among the adolescents in an urban area in Korea. Journal of Korean Neuropsychiatric Association. 2001;40(4):627-39.

23. AI-Marri A. INTERNATIONAL JOURNAL OF SCIENTIFIC RESEARCH.

24. Lutfi M. A Comparative Study between the Prevalence of Depression Disorder and Anxiety Disorder in Egyptians Adolescents Practitioners and non-Practitioners of Sports.

25. Adlina S, Suthahar A, Ramli M, Edariah A, Soe S, Mohd FA, et al. Pilot study on depression among secondary school students in Selangor. The Medical journal of Malaysia. 2007;62(3):218-22.

26. Maharaj R, Alli F, Cumberbatch K, Laloo P, Mohammed S, Ramesar A, et al. Depression among adolescents, aged 13-19 years, attending secondary schools in Trinidad prevalence and associated factors. West Indian Medical Journal. 2008;57(4):352-9.

27. Erulkar AS, Mekbib T-A, Simie N, Gulema T. Migration and vulnerability among adolescents in slum areas of Addis Ababa, Ethiopia. Journal of Youth Studies. 2006;9(3):361-74.

28. Nguyen DT, Dedding C, Pham TT, Wright P, Bunders J. Depression, anxiety, and suicidal ideation among Vietnamese secondary school students and proposed solutions: a cross-sectional study. BMC Public Health. 2013;13(1):1195.

29. Yang J, Yao S, Zhu X, Zhang C, Ling Y, Abela JR, et al. The impact of stress on depressive symptoms is moderated by social support in Chinese adolescents with subthreshold depression: A multi-wave longitudinal study. Journal of Affective Disorders. 2010;127(1-3):113-21.

30. Homan GJ. Failure to thrive: a practical guide. Am Fam Physician. 2016;94(4):295-9.

31. Dozier M, Stoval KC, Albus KE, Bates B. Attachment for infants in foster care: The role of caregiver state of mind. Child development. 2001;72(5):1467-77.

32. Wilson SR, Rack JJ, Shi X, Norris AM. Comparing physically abusive, neglectful, and non-maltreating parents during interactions with their children: A meta-analysis of observational studies. Child Abuse \& Neglect. 2008;32(9):897-911.

33. Pagliaccio D, Luby JL, Bogdan R, Agrawal A, Gaffrey MS, Belden AC, et al. Stress-system genes and life stress predict cortisol levels and amygdala and hippocampal volumes in children. 
Neuropsychopharmacology. 2014;39(5):1245.

34. Rubin KH, Coplan RJ, Bowker JC. Social withdrawal in childhood. Annual review of psychology. 2009;60:141-71.

35. De Bellis MD. The psychobiology of neglect. Child maltreatment. 2005;10(2):150-72.

36. Pollak SD, Cicchetti D, Hornung K, Reed A. Recognizing emotion in faces: developmental effects of child abuse and neglect. Developmental psychology. 2000;36(5):679.

37. Audage NC, Middlebrooks JS. The Effects of childhood stress on health across the lifespan. 2008.

\section{Figures}

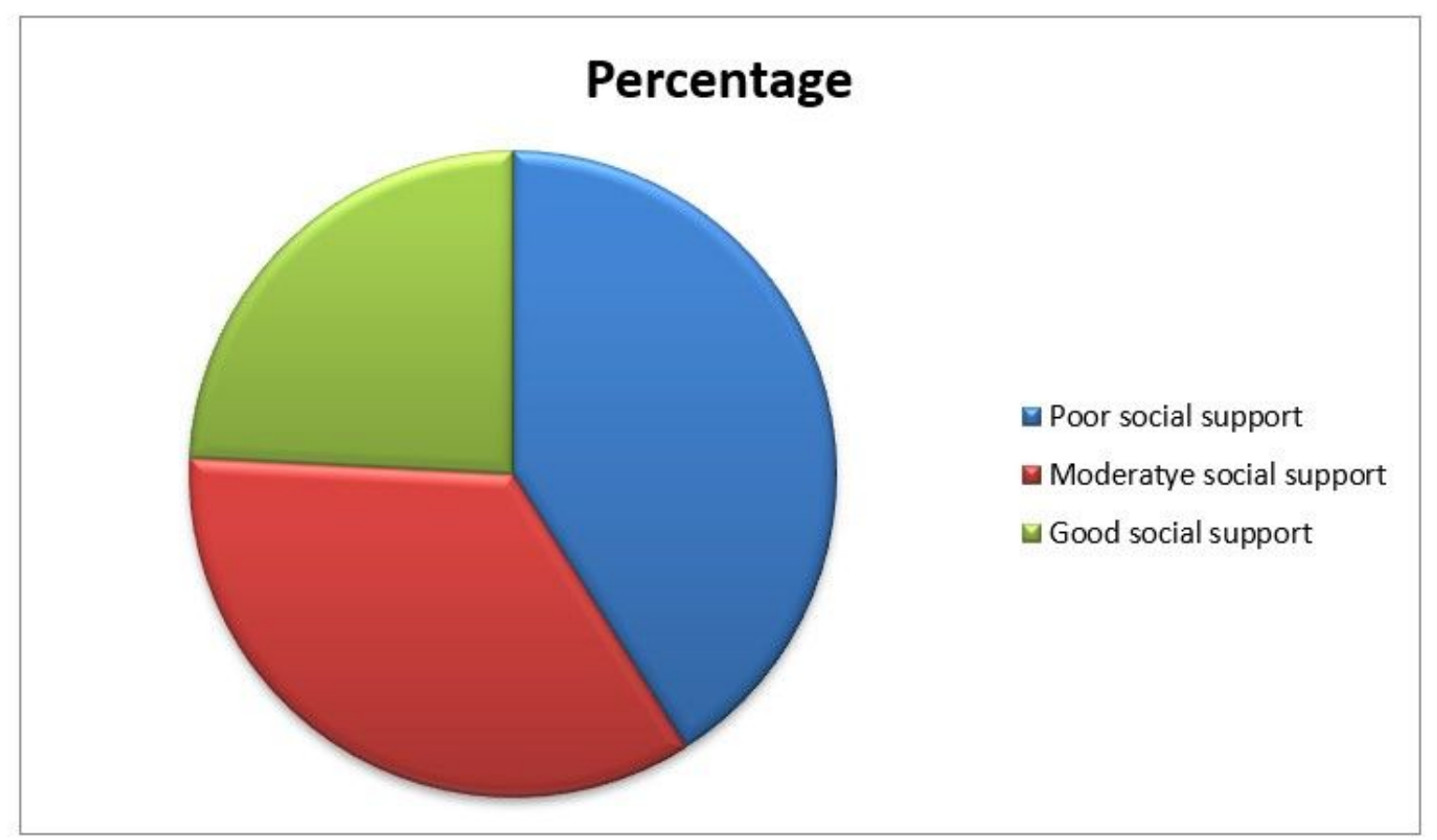

\section{Figure 1}

Distribution of the level of social support among high school students at Aksum town, $2019(n=624)$ 


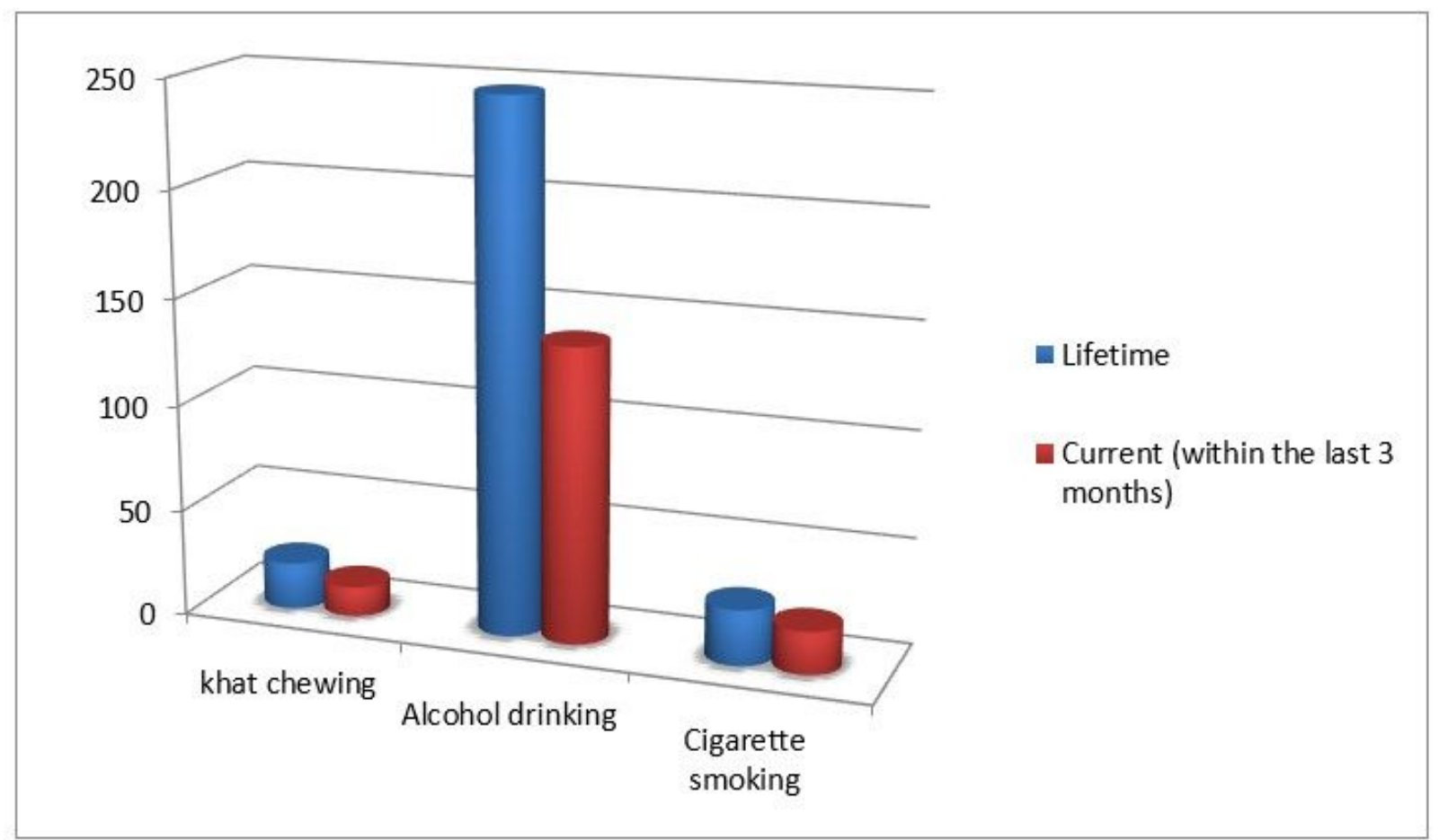

Figure 2

Distribution of substance-related factors among high school students at Aksum town, $2019(n=624)$ 


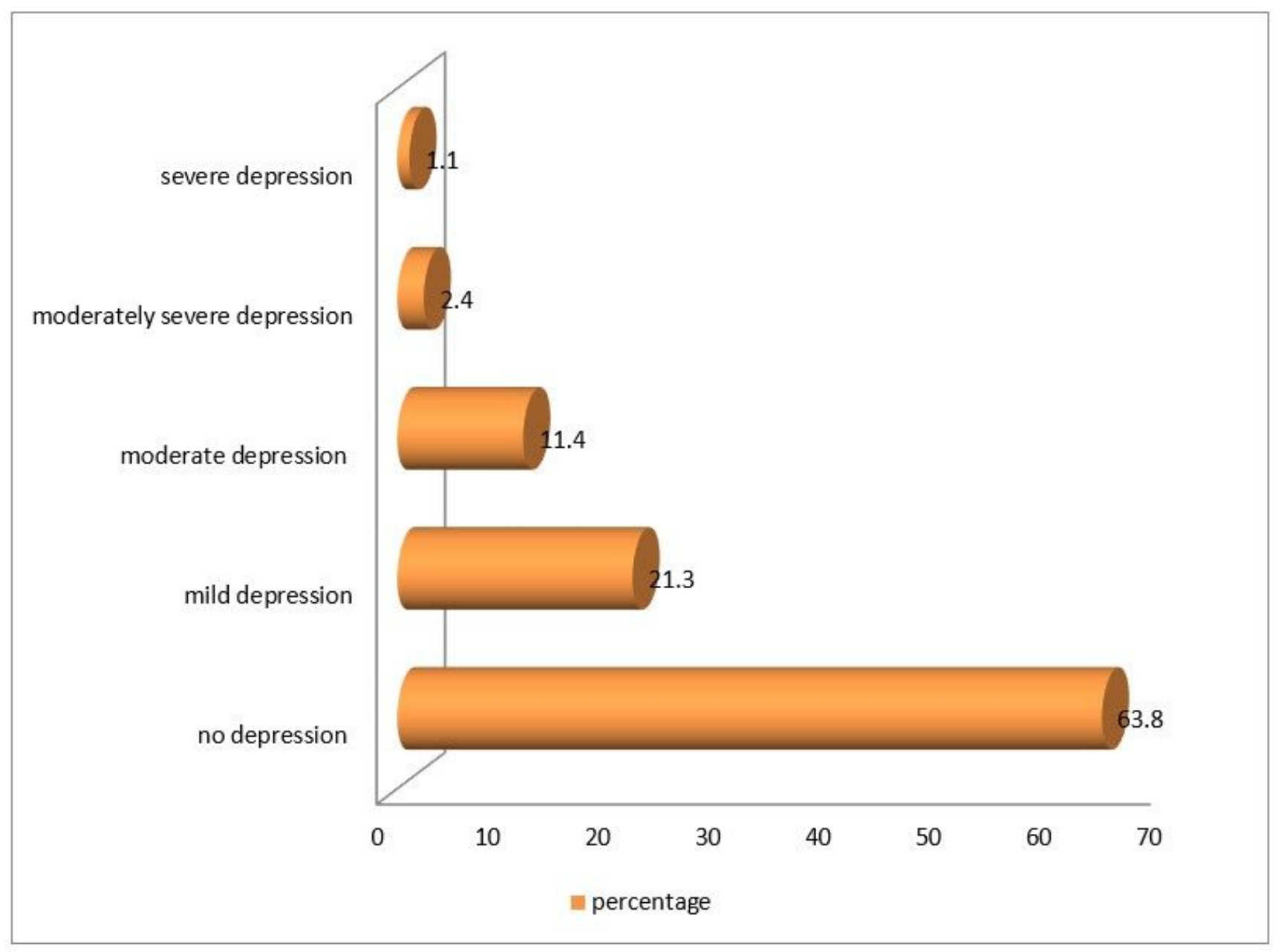

\section{Figure 3}

characterization of depression severity among adolescents in governmental high schools at Aksum town, $2019(n=624)$ 